\title{
Study on Micro-teaching Instructional Design Based on Cognitive Rules
}

\author{
Qinghui Zhou ${ }^{\mathrm{a}}$, Siyuan $\mathrm{Lu}^{\mathrm{b}}$ \\ School of Mechanical-electronic and Vehicle Engineering, Beijing University of Architecture and \\ technology, China \\ aemail: qhzhou@yeah.net, bemail: lusiyuan1208@163.com
}

Keywords: Micro-teaching. Instructional Design. Cognitive Rules.

\begin{abstract}
Micro-teaching has a rapid development in recent years in China. As a most important part of micro-teaching, instructional design is elaborated in four areas, clearing teaching object, designing micro-lessons based on cognitive rules, reasonable analysis method and appropriate blackboard design. The lesson "Automotive air conditioning" is taken as an example. Firstly, the topic is introduced to the new contents through two common questions. And then, the structural principle of air conditioning is analyzed from analog methods. Finally, fault detection and diagnosis methods of air conditioning are learned through case study. The result shows that the instructional design has an excellent effect in teaching activities, therefore, the micro-teaching has won a third prize in national competition in China.
\end{abstract}

\section{Introduction}

Micro-teaching represents a new idea and way of resources development. With the development of society, the progress of time, the wide usage of modern information technology, micro-teaching is a kind of rapidly developed form on innovation education which has many characters such as various methods, obvious topic, and short and small details. Based on this technique, micro-teaching is carried out in 10-15 minutes periods with a narrow scope. It is a small but integrated teaching activity which centers with the resource of micro video, and match with other education resources. The rapid development of micro teaching accords with the cognitive psychology which can reduce the cost of education and expand the influence.

Innovative teaching methods are the key to improving teaching quality. When the teaching aim and contents is confirmed, whether the teaching methods are appropriated is very important for student to understand knowledge, develop abilities and train skills. Because micro-teaching is an innovative teaching method itself which determining that it must have a huge difference from all kinds of traditional teaching forms, it can push the reform of lesson system and content. A subject and a curriculum can be specially designed for students and meet their requirement throng micro-teaching development in which approach is more in line with the needs of curricula. And then, the cognitive sense of student is concerned in the teaching progress, therefore, micro-teaching should also emphases on helping students develop a proactive learning attitude.

Instructional design is the most important part of teaching methods in micro-teaching based on the above explanation, because it must be considered in all the ranges, such as teachers and students, teaching ways and methods, etc. In order to improve the teaching effect, the paper analyzes the various aspects of micro-teaching instructional design and demonstrates its practical manners with examples.

\section{Instructional Design}

Micro-teaching is only around 20 minutes, which makes difficult questions to be easily understood in quite a short time. To solve questions clearly, a careful and detailed instructional design is made in the teaching activities. It's mainly reflected in four areas in the study:

\section{Defining the teaching objects}


Defining the teaching objects is the most important part in micro-teaching instructional design. Only when "who are the lessons for" is made sure, the appropriate teaching materials and method can be chosen. The lesson "Automotive Air Conditioning" mainly faces to the applied type of undergraduate students. Before this lesson, the students are quite ignorant of basic principles, and only have limited knowledge of air conditioning, such as air conditioning shape and operate buttons. Due to lack of energy-related theoretical knowledge, it's impossible for the students to derive the law of air conditioning from formulas and parameters. Meanwhile, students don't have experience in the maintenance and operation of air conditioning. They are still not clear about the structure of air conditioning. Based on these issues, the solution is: starting from the well-known "operate buttons", we combine "vehicle shape", "air conditioning position" and "air conditioning buttons", which students have already understood and mastered, with the unknown theory "works" and reach the purpose of cognition.

\section{Designing micro-teaching based on cognitive rules}

The purpose of the micro-lesson design is to improve teaching efficiency. Teacher can't decompose an issue carefully or expand the description in detail, because the micro- teaching time is very short. How to make the students understand the difficulty and focus in a short time? The main factor in the success of micro-lesson is to choose the appreciate contents and designs based on cognitive rules, as shown in Fig. 1

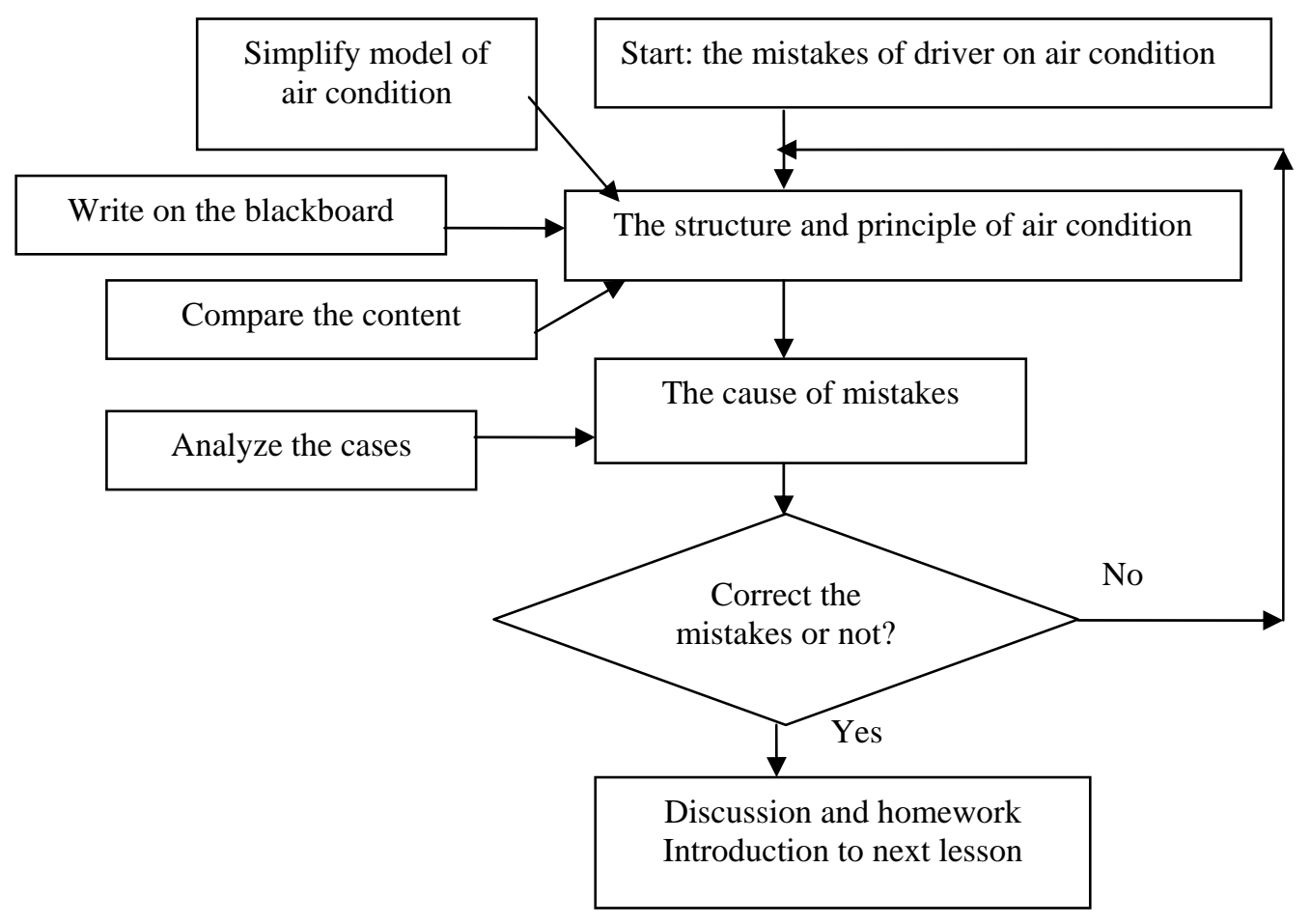

Fig.1 The idea of instructional design

The application of cognitive rules is shown in Fig.1 when explaining the work principle of air condition in automotive. Namely: understanding a thing is a dialectical process from the phenomenon to the reason, to the essence, to the new phenomenon, and to the new issues which lead to the next lesson.

First, micro-teaching cases should be typical and understandable. For example: in order to allow students to understand the performance of automotive air-conditioning equipment and works in a short time, especially the reasons for a failure, some very typical case should be chosen, especially the actual case that taken place in students themselves. Students have personal feelings, so that it is impressive and easy to understand. Second: the initial part of the micro- lesson should grab the attention of students in a short time. Focus can greatly help students improve learning efficiency. In the micro-teaching of automotive air conditioning, if the lesson is begun from the "air button" and so 
on, it will become simple and lost its attractive force. How to improve students' interests? Its solution is to start from a problem which is frequently encountered. That is, teacher can introduce the course through the two "owners of the correct operation of the air conditioning", analyze the reasons for its error, and then propose solutions to the wrong way. When analyzing the reasons of the error, teacher should properly introduce the main content of "automotive air conditioning". Finally, the new problem of "can opening air window save the costs of energy "leads to the next section as a guide, so that the cycle of the loop. The design process of the micro- lesson, according to ideas of asking questions, analyzing problems and solving problem, makes the curriculum idea natural clarity in line with cognitive rules. In various parts of the convergence of micro- lesson, using well-known knowledge transition to the next part of the guide, with the exact logical connection between the parts, the span is not too large. PPT used in some duplication between the various parts of the corresponding picture or text, indicates the smooth transition between them which allows students to accept the new learning content more easily.

\section{Analyzing the problem clearly and reasonably}

For science and engineering course, the theories and principles are difficult and deep. But for the applied type of undergraduate students, their knowledge has yet not enough to understand the theories and principles directly, therefore, when analyzing the problems, the best method is analogy. In analogizing, teacher should pay attention to the example which is moderated, not too simple and not too deep. Simple examples have not enough attraction, but deep examples have not been understood easier. So, the suitable example can get together with student's modern thinking life to improve their rich imagination. For example: in teaching four working process that "compression- condensation throttle - evaporation", the analogy method are all used to make the abstract concept become concrete and vivid. The analogizing method of compressor is shown in Fig.2. The principle of compressor is similar to the inflator which is known for the students. When the air is compressed, its pressure should be increased.

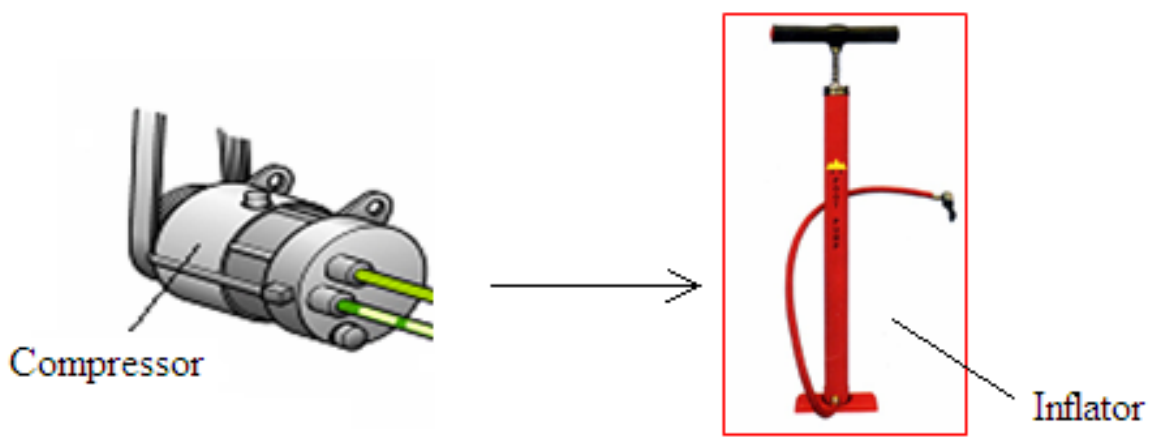

Fig. 2 the analogy method of compressor in micro-teaching

Especially the two concepts, condensation and evaporation are very similar, but their difference is very big, so making examples will be just perfect, otherwise the two concepts is easy to make student be confused. And next, in the process of teaching "air conditioner simple detection", the method in the simplest hands- touching way makes the content get vivid and specific.

\section{Properly writing on the blackboard}

The outline on the blackboard can make students understand easily and clearly. In order to emphasize the effect, the four work process, "compression-condensation-throttle- evaporation", is written on the blackboard in repeat. In the design process, the design line is simple and clear on the blackboard. This case will use the number "1, 2, 3, 4" to list the emphasis of lesson. And a total of 32 Chinese words are in the blackboard, which can present the key problems on the blackboard to stick out a mile. The content on the blackboard is shown as following.

Firstly: Compression: low-pressure air to high-pressure air

Secondly: Condensation: high-pressure air to high-pressure liquids

Thirdly: Throttle: high-pressure liquids to low-pressure liquids

Finally: Evaporation: low-pressure liquids to low-pressure air 
The whole cooling process is from compression (first process) to evaporation (final process). And next, the cycle process comes back the compression from Evaporation. Thus, the cooling process is to achieve the purpose of cooling by cycle to cycle.

\section{Summary}

In short, mainly to stimulate the interest of students, the instructional design aimed at the teaching object to select the correct content material and reasonable analysis method, organized teaching contents in according to the cognitive rule. Through the micro-teaching, the students who is not fundamental can acquire knowledge, understand the abstruse theory and abstraction, the students who is interested can access to referring information to continue learning and researching in-depth.

The web site of the micro-teaching is http://weike.enetedu.com/play.asp?vodid=150047 which takes part in the national universities competition in 2013. The competition result shows that the instructional design has an excellent effect in teaching activities; therefore, the micro-teaching has won the third prize in national competition in China.

\section{Acknowledgements}

The study is a project supported by Scientific Research Common Program of Beijing Municipal Commission of Education (KM201110016013 ) and Academic Human Resources Development PHR(IHLB)201108203 and PHR(IHLB)201106125.

\section{References}

[1] Chen lan, Xiao Guiqiao, Wang Ying, etc. the discuss on micro-teaching design Journal of Jiangxi Vocational and Technical College of Electricity Vol.26(2).2013 pp80-83 In Chinese

[2] Arzu Tadelen Karçkay, eyda Sanlı The effect of micro teaching application on the preservice teachers'teacher competency levels Procedia Social and Behavioral Sciences 1 (2009) 844-847.

[3] Pawar Vatsala Udhav;jitendra Jalkute A Survey And Study Of The Students Towards Micro Teaching Programme For Improving Teaching, Skill Indian Streams Research Journal, Vol.11 (2012) pp562-564

[4] Napoles, Jessica Relationships Among Instructor, Peer, and Self-Evaluations of Undergraduate Music Education Majors" Micro-Teaching Experiences, Journal of Research in Music Education, Vol.56(2008), pp82-91

[5] Yigit,N Developing presentation skills of student teachers through micro-teaching method, Energy Education Science And Technology Part B-Social And Educational Studies, Vol.2(2010),pp55-74 